\title{
SUBVERSÃO E RESISTÊNCIA NO GT 23 DA ANPED A PARTIR DE MICHEL FOUCAULT
}

\author{
Anderson Ferrari ${ }^{i}$ \\ Danilo Araujo de Oliveira ${ }^{\text {ii }}$
}

\begin{abstract}
Resumo: Os trabalhos apresentados no Grupo de Trabalho (GT) 23 da ANPEd - Gênero, Sexualidade e Educação - nos inspiraram a escrever este artigo que toma como foco as potencialidades do arcabouço foucaultiano, especificamente as discussões presentes no livro "História da Sexualidade I: a vontade de saber", obra mais referendada nos trabalhos em que Foucault aparece. Qual a importância dessa obra para além dela? Quais os efeitos das análises para colocar sob suspeita nossas formas de pensar, de ser e estar no mundo? Foram essas duas questões problemas que organizaram nossas análises, possibilitando-nos dividir o artigo em três pontos de discussão: a fidelidade infiel a Foucault, Foucault como instaurador de discursividade e os conceitos de subversão e resistência na "História da Sexualidade I".
\end{abstract}

Palavras-chaves: Educação, Foucault, GT 23.

\section{SUBVERSION ANDA RESISTANCE IN ANPED's GT 23 FROM MICHEL FOUCAULT}

\begin{abstract}
The works presented in the Working Group (GT) 23 of Anped - Gender, Sexuality and Education - inspired us to write this article that focuses on the potentialities of the foucauldian framework, specifically the discussions around sexuality present in the book "History of Sexuality I: the will to know ", a work more endorsed in the works in which Foucault appears. What is the importance of this work beyond it? What are the effects of the analysis to put our ways of thinking, of being in the world under suspicion? These two issues were problems that organized our analyzes, enabling us to divide the article into three points of discussion: unfaithful fidelity to Foucault, Foucault as an instigator of discourse and the concepts of subversion and resistance in the "History of Sexuality I".
\end{abstract}

Keywords: Education, Foucault, GT 23.

O novo não está no que é dito, mas no acontecimento de seu retorno (Michel Foucault, 1996, p.26)

\section{Introdução}

A proposta de um dossiê com o título "Itinerâncias entre Michel Foucault e Educação" nos coloca uma questão inicial: quais os efeitos do pensamento foucaultiano em um campo de conhecimento como a Educação? Uma pergunta fundamental para pensar o impacto de um filósofo que não se dedicou a 
problematizar a educação de forma direta. No entanto, o tipo de inquietações e de pesquisas implementadas por Foucault foi capaz de desenvolver um pensamento transversal que impactou em diferentes áreas, dentre elas, a Educação.

Alfredo Veiga Neto (2003), ao escrever um livro com essa mesma temática - Foucault e a Educação -, argumentou que faltava um livro que explicasse a filosofia de Michel Foucault para a educação. Um livro que facilitasse a compreensão do "que ele escreveu sobre o sujeito, os saberes, os poderes e as instituições modernas, mas que também discutisse o que se pode e o que não se pode fazer com ele e a partir dele e o quão produtivo tudo isso é para a Educação" (VEIGA-NETO, 2003, p.8). A partir dessa provocação de Veiga Neto (2003) é que queremos pensar o que podemos fazer com Michel Foucault e para além dele.

Considerando que essa influência se deu em maior grau em determinadas áreas da Educação, fomos buscar, na principal associação de pesquisa em educação do Brasil - Associação Nacional de Pesquisas em Educação (ANPEd) -, dados que nos possibilitem construir análises sobre a influência do pensamento transversal de relação gênero, sexualidade e educação. Dois motivos foram definitivos para nossa escolha por essas temáticas. O primeiro é o fato de ser essa nossa área de pesquisa e investigação ao longo dos anos, interessados nas construções das homossexualidades masculinas em diferentes contextos, sobretudo nas escolas. A segunda motivação foi baseada nos atuais ataques que essa área vem sofrendo, o que nos exige um tipo de resistência criativa e inventiva, o que vai ao encontro da potencialidade do arcabouço foucaultiano.

Em 2003, na 26a reunião anual da ANPEd, um grupo de pesquisadores e pesquisadoras encabeçaram a proposta de criar um Grupo de Trabalho novo, intitulado "Gênero, Sexualidade e Educação", sob o argumento que essa era uma área com um campo de pesquisa, de grupos de estudos e de investigação na pós-graduação já consolidados. Essa situação - um campo já consolidado e a ausência de um GT específico - fazia com que as discussões de gênero e sexualidade estivessem presentes nas reuniões da ANPEd em diversos Grupos de Trabalho, como Movimentos Sociais, Formação de Professores, Currículo e Sociologia da Educação. Com base nesses argumentos, foi aprovada a proposta para a construção de um Grupo de Estudos (GE), segundo a regulamentação da Associação, para, só em 2006, ser transformado em Grupo de Trabalho. Desde essa data, o GT 23 se tornou um "espaço legitimado no interior da mais importante associação brasileira de educação, para constituir uma rede que ampliasse as possibilidades para as visibilidades e para o fortalecimento do campo marcando uma consolidação acadêmica e política" (RIBEIRO \& FILHA, 2014, p. 2).

Já se passaram 15 anos da criação do GT 23 - Gênero, Sexualidade e Educação e, nesse período, podemos perceber as transformações no que diz respeito às temáticas, que dialogam com as questões sociais e políticas nacionais. No entanto, um fato nos chama atenção: a influência do pensamento de Michel Foucault nesse GT, algo que sempre esteve presente e continua atual, o que nos permite afirmar que ele é 
o autor mais utilizado nos trabalhos. Para constatar essa presença, fizemos uma pesquisa na página oficial da ANPEd, considerando o período de existência do GT, ou seja, da $29^{\mathrm{a}}$ reunião anual, em 2006, à 39a reunião anual, o que significa dizer que o nosso recorte temporal vai de 2006 a 2019 . Do total de $167^{\mathrm{iii}}$ trabalhos disponibilizados na página, distribuídos nas 11 reuniões anuais, 89 deles citaram ou tomaram como referência algum livro de Michel Foucault, de maneira que podemos afirmar que ele é o autor mais utilizado nos trabalhos apresentados no GT.

Nosso procedimento metodológico para esta pesquisa foi acessar a página da ANPEd e acessar cada uma das reuniões anuais, com o objetivo de verificar, no GT $23^{\text {iv }}$, a presença de obras de Michel Foucault. Em cada trabalho publicado na página, nós buscávamos as referências ao autor, considerando que o conjunto do que ele escreveu engloba seus livros, cursos, entrevistas e artigos presentes em outros livros organizados. Ao final, verificamos que a utilização de Michel Foucault está centrada nos livros ${ }^{\mathrm{v}}$, que eram os mais citados, como pode ser visto na tabela abaixo, construída por nós após essa primeira etapa da pesquisa. Ressalte-se que nos 89 trabalhos que citaram algum escrito de Michel Foucault, o destaque é a "História da Sexualidade I", que aparece em 49 deles.

Tabela 1 - Relação livro e trabalhos em que é referência

\begin{tabular}{|l|c|}
\hline \multicolumn{1}{|c|}{ Livro } & $\begin{array}{c}\text { No de trabalhos } \\
\text { em que é } \\
\text { referência }\end{array}$ \\
\hline A Arqueologia do Saber & 22 \\
\hline A Coragem da Verdade: o governo de si e dos outros & 02 \\
\hline A hermenêutica do sujeito & 02 \\
\hline A ordem do discurso & 18 \\
\hline As palavras as coisas: uma arqueologia das ciências humanas & 04 \\
\hline $\begin{array}{l}\text { Ditos e Escritos II: Arqueologia das Ciências e História dos Sistemas de } \\
\text { Pensamento }\end{array}$ & 01 \\
\hline Ditos e Escritos IV: estratégia, poder-saber & 06 \\
\hline Ditos e Escritos V: Ética, Sexualidade, Política & 15 \\
\hline Ditos e Escritos VI: Repensar a Política & 02 \\
\hline Do governo dos vivos & 01 \\
\hline El yo minimalista e otras conversaciones & 02 \\
\hline Em defesa da sociedade & 06 \\
\hline Herculine Barbin: o diário de um hermafrodita & 01 \\
\hline História da Sexualidade I: a vontade de saber & $\mathbf{4 9}$ \\
\hline História da Sexualidade II: O uso dos prazeres & 12 \\
\hline História da sexualidade III: Cuidado de si & 06 \\
\hline Microfísica do poder & 22 \\
\hline Nascimento da Biopolítica & 06 \\
\hline O Belo Perigo & 01 \\
\hline O nascimento da clínica & 01 \\
\hline Os anormais & 05 \\
\hline Resumo dos Cursos do Collège de France & 01 \\
\hline Segurança, território, população & 05 \\
\hline
\end{tabular}




\begin{tabular}{|l|l|}
\hline Tecnologías del yo y otros textos afines & 04 \\
\hline Um diálogo sobre os prazeres do sexo: Nietzche, Freud e Marx & 02 \\
\hline Vigiar e punir: nascimento da prisão & 26 \\
\hline
\end{tabular}

Fonte: Elaborada pelos autores, 2020.

Com base nessa tabela, é possível constatar a forte presença da obra "História da Sexualidade I: a vontade de saber", como talvez já fosse esperado, em se tratando de um GT que tem como foco da discussão a relação entre gênero, sexualidade e educação. Passamos, então, para a segunda etapa da pesquisa, que foi ler somente os trabalhos em que essa obra era referência, para pensar como ela influenciou essa área do conhecimento, ou seja, qual a contribuição da obra para o GT 23.

Nosso foco de análise está na importância da obra para além dela, concentrando nos efeitos das análises para colocar sob suspeita nossas formas de pensar, de ser e estar no mundo. Nesse sentido e, diante da impossibilidade de trabalhar com todos os artigos que tomaram essa obra de Michel Foucault como referência, optamos por centrar nossa análise em três partes. Na primeira, analisamos os significados da fidelidade infiel a Foucault e como essa postura abre novas possibilidades de pesquisa e de construção do conhecimento a partir do contexto brasileiro. Em seguida, tomamos a definição de instaurador de discursividade para recuperar as análises dos três conceitos que unem os trabalhos no GT 23: sujeito, discurso, verdade, poder-resistência. Ao final, com base nas discussões anteriores, debruçamo-nos sobre os conceitos de subversão e resistência na História da Sexualidade I, tomando como detonador os trabalhos que se dedicaram a investigar a presença de transexuais e travestis nas escolas. Em todas essas partes, vamos fazer referências a alguns trabalhos apresentados, utilizando-os como exemplos das análises que queremos fazer da importância da obra "História da Sexualidade I" para a construção do campo do gênero, sexualidade e educação.

\section{A fidelidade infiel como característica do GT 23}

Essa expressão fidelidade infiel nos chegou ainda na primeira fase da pesquisa, depois da constatação dos diferentes usos das obras de Michel Foucault nos trabalhos do GT 23. Na segunda etapa da pesquisa - após constatar que o livro "História da Sexualidade I: a vontade de saber" (HSI) é o livro mais utilizado nos trabalhos apresentados -, ao agruparmos os textos por temáticas, percebemos que elas eram variadas. Trata-se de temas e situações que dizem de sujeitos que assumem um certo jeito transgressivo de ser e estar no mundo. Assim, os trabalhos nos ajudam a problematizar como vamos construindo isso que chamamos de realidade, de escola, de professor e professora, organizados pelas relações de gênero e sexualidade. Dessa forma, o resultado encontrado foi o seguinte: Homossexualidades (FERRARI, 2006); Deficiência (CAMPOS, 2006); Feminilidade (XAVIER, 2006; VARGAS, XAVIER, 2013; NEVES, 2019); 
Infâncias (CRUZ, 2006; MEIRELES, 2009; RIBEIRO, 2012; PEREIRA, 2017); Escola (BALESTRIN, 2007; RIBEIRO, 2012; NEVES, 2012; GOETTEMS, SCHWENGBER, WISNIEWSKI, 2017; ALMEIDA, 2017); Docência (SILVA, 2007; ALMEIDA, 2009; CASTRO, 2009; BASSALO, 2009; SILVA, SIQUEIRA, 2012; RIZZATO, 2010; CASTRO, 2015; SOUZA, 2015; PARREIRA, SILVA, 2015), Literatura (SILVA, SIQUEIRA, 2008); Pedagogia Queer (CÉSAR, 2008); Educação sexual (CASTRO, 2008; XAVIER FILHA, 2009); Escrita (SOUSA, 2008; CASTRO, 2013); Transexualidade (CÉSAR, 2009; TORRES, 2013; SANTOS, 2013; SANTOS, 2015; SEVILLA, 2015; SANTOS, 2017; SANTOS, 2019); Família (FERNANDES, 2009); Homoparentalidade (REALI, 2009); Mídia (SCHWENGBER, 2009); Ensino de ciências (SILVA, 2012); Maternidade (RITTI, 2013; SCWENGBER, 2015); Gentrificação (PORTINARI, 2015); Psiquiatrização da educação (NOGUEIRA, 2015); Corpo (MORESCO, 2017); Políticas educacionais (MOREIRA, 2017; SIERRA, 2012), Juventudes (KLEIN, 2019).

A partir desse resultado, argumentamos que há, no GT23, uma fidelidade infiel a Foucault, o que possibilita uma profusão de temas nos trabalhos apresentados, os quais tomam as teorizações foucaultianas como caixa de ferramentas para abordagens de gênero e sexualidades, como provocações para construir pesquisas autorais a partir do contexto brasileiro. Essa diversidade de temas nos remete à potencialidade do arcabouço foucaultiano: como um pensamento educacional que se abre à problematização do presente e do sujeito pode alargar as possibilidades de pesquisa com as teorizações genealógicas de Foucault?

A expressão fidelidade infiel é atribuída a Jacques Derrida (SANTOS; HADDOCK-LOBO, 2018), escritor francês que provocou modificações na língua francesa a partir dos usos que ele fazia dela, torcendo o léxico, a sintaxe e a semântica. Em sua última entrevista, ele caracteriza essa fidelidade infiel a uma forma de violência com respeito e refinamento que ele faz com a língua. $\mathrm{O}$ autor demonstra, assim, que a língua é móvel e é vida. E é essa mesma relação que ele quer explorar com os textos, levando-os "ao limite do que podem dizer, investindo naquilo que, neles, abre espaço para o movimento de diferenciação", de modo que a fidelidade infiel explora não "o significado oculto de um texto, a verdade sobre o que um pensador quis dizer, mas aquilo que escapa à representação da plenitude de um sistema de signos, de seu funcionamento inconteste" (SANTOS; HADDOCK-LOBO, 2018, p. 159).

É esse movimento de diferenciação possível, quando se tem essa forma de fidelidade, que parece interessar aos/às estudiosos/as foucaultianos/as, fazendo suas teorizações se desdobrarem em diversas pesquisas e reflexões no campo da Educação. De acordo com Veiga-Neto, no que se refere a Foucault, "ser pertinente em relação ao seu pensamento não implica uma fidelidade irrestrita ao filósofo", pelo contrário, implica abrir novos caminhos, de modo a examinar "seus conceitos e os encaminhamentos que ele deu às suas investigações, para segui-los naquilo em que eles podem ser úteis e importantes para nossas próprias investigações" (VEIGA-NETO; RECH, 2014, p. 72). O próprio Foucault já havia falado desse investimento 
que ele mesmo fazia a propósito dos seus usos com Nietzshe: "O único sinal de reconhecimento que se pode ter para com um pensamento como o de Nietzsche, é precisamente utilizá-lo, deformá-lo, fazê-lo ranger, gritar. Que os comentadores digam se se é ou não fiel, isto não tem o menor interesse" (FOUCAULT, 1981, p.143).

Essa última citação do Foucault não nos deixa apenas vestígios metodológicos de como o autor trabalhava, mas amplia os modos de desenvolver pesquisas com as teorizações foucaultianas que as tome como experiências e ferramentas que podem ter usos múltiplos. Em outro momento, Foucault ressalta de que forma o pensamento dele se insere nas relações de poder para produção da verdade e como podemos utilizá-lo:

\begin{abstract}
Meu discurso é, evidentemente, um discurso de intelectual e, como tal, opera nas redes de poder em funcionamento. Contudo, um livro é feito para servir a usos não definidos por aquele que o escreveu. Quanto mais houver usos novos, possíveis, imprevistos, mais eu ficarei contente. Todos os meus livros seja História da loucura seja outros podem ser pequenas caixas de ferramentas. Se as pessoas querem mesmo abri-las, servirem-se de tal frase, tal ideia, tal análise como de uma chave de fenda, ou uma chave-inglesa, para produzir um curto-circuito, desqualificar, quebrar os sistemas de poder, inclusive, eventualmente, os próprios sistemas de que meus livros resultam, pois bem, tanto melhor! (FOUCAULT, 2006, p. 52).
\end{abstract}

Nesse sentido, parece-nos importante evidenciar os usos novos, possíveis e imprevistos de Foucault no GT23, no qual se desdobram diferentes temáticas e estudos que não estão preocupados em apenas dizer ou difundir as teorizações foucaultianas, mas fazer algo com elas, colocar o conhecimento em movimento de modo a violentar o presente da forma como o vemos, como "dado", constituído de uma vez por todas.

Dessa maneira, a pergunta inicial que fizemos - como um pensamento educacional que se abre à problematização do presente e do sujeito pode alargar as possibilidades de pesquisa com as teorizações genealógicas de Foucault? - pode nos indicar que esse pensamento educacional tem algo em comum, mas, ao mesmo tempo, é heterogêneo e marcado pela invenção. Iremos, então, tratar do que une esses trabalhos e, em seguida, dizer de que forma essa unidade se multiplica pela afirmação da vida na educação. A fidelidade infiel dos trabalhos se afasta de uma forma de utilizar autores como Michel Foucault que consiste em redizer o que o filósofo já escreveu ou mesmo traduzir suas ideais. Eles se dedicaram a proliferar as ideias do autor para dar vida a novos discursos sobre gênero, sexualidade e educação, como um instaurador de discursividade.

\title{
Foucault, o instaurador de discursividade
}

O termo instaurador de discursividade foi utilizado pelo próprio Foucault, como nos lembra Sílvio Gallo (2014): 
um "instaurador de discursividade", como uma "função autor", que ele caracteriza como sendo a "característica do modo de existência, de circulação e de funcionamento de certos discursos no interior de uma sociedade" (GALLO, 2014, p. 16).

Como instaurador de discursividade, o que a presença de Foucault no GT 23 nos provoca é pensar sua utilização como um movimento que faz circular e funcionar "certos discursos" no campo das relações de gênero, sexualidade e educação. Se "História da Sexualidade I" é o livro mais utilizado, é importante dizer que ele estabelece diálogo com as outras obras em torno da construção de um arcabouço teórico do autor que tem que ser visto ao longo de sua trajetória de investigação e produção.

\begin{abstract}
Os instauradores de discursividade não se limitam aos textos que escreveram, mas produzem um novo campo de investigações, de possibilidades de pensamento, de enunciação de discursos. Quando uma função autor passa a operar como instauradora de dis-cursividade, vê-se um movimento de reatualização, de renovação, de reativação de discursos. Um movimento que implica a produção de discursos novos, os quais, embora guardem relação com a função autor que os originou, são novos discursos que não se importam em ser "fiéis” àquela origem (GALLO, 2014, p. 16-17).
\end{abstract}

Operar com Foucault diz de assumir uma perspectiva para a pesquisa, o que implica tomar alguns importantes conceitos para guiar as problematizações e como esses conceitos foram sendo reatualizados, renovados e reativados a partir do contexto educacional brasileiro no campo do gênero, sexualidade e educação. Sujeito, discurso, verdade, poder/resistência são alguns desses conceitos centrais que unem essas pesquisas e o modo como diversos/as autores/as lançam problematizações sobre seus objetos. O sujeito em Foucault não existe a priori, não é dado. Isso significa dizer que, quando problematizamos o sujeito, procuramos mostrar os processos de subjetivação, como cada sujeito se constitui como tal.

Esse processo, de acordo com Foucault (2014b), se dá a partir de três modos: a) modos de objetivação, b) práticas divisoras e c) maneiras que um ser humano pode tornar-se sujeito de si mesmo. O primeiro diz de uma atuação dos discursos nos quais se toma o sujeito como objeto, como faz, por exemplo, a gramática, a filosofia, a linguística e a ciência. O segundo diz da divisão do sujeito em seu interior e em relação aos demais, de modo que há a separação dos sujeitos entre louco e são, doente e sadio, homossexual e heterossexual, anormal e normal etc. Isso nos permite evidenciar que os sujeitos são produzidos a partir de práticas de divisão, separação, inclusão, exclusão. Por último, considera-se que não somente a partir de práticas de dominação que o sujeito é constituído, mas os indivíduos agem sobre si próprios, efetuando uma série de operações sobre si para se tornarem sujeitos. No que se refere à sexualidade, por exemplo, a preocupação de Foucault em "História da Sexualidade I" - livro base na maioria das pesquisas do GT23 é a maneira como o indivíduo aprende a se reconhecer como sujeito de uma sexualidade.

Algo que aparece, por exemplo, nos seguintes trabalhos: Ferrari (2009); Cruz (2009); Balestrin (2007); Silva (2007); Castro (2010). Nesse sentido, considerando um efeito dos discursos, historicamente construídos acerca da homossexualidade, Anderson Ferrari (2009, p. 4) busca "verificar como os grupos estão trabalhando na problematização das práticas e discursos que estão construindo as imagens e 
identidades dos homossexuais presentes na cultura”. Considerando também a produção do sujeito, outra pesquisa mostra como, “em nosso tempo histórico, num jogo de poder-verdade-saber”, os discursos operam "inventando" aqueles que chamamos de crianças adolescentes vivendo com HIV/AIDS" (CRUZ, 2009, p. 2). A sexualidade na constituição dos sujeitos é problematizada ainda em um outro trabalho para demonstrar "até que ponto os feminismos estão dando conta das discussões sobre sexualidade e a implicação deste campo (da sexualidade) na vida de mulheres e homens" (BALESTRIN, 2007, p. 4). O sujeito, tal qual apresentado em HSI e nos trabalhos aqui abordados é uma invenção, é um efeito e produção do discurso. Discurso entendido como prática que constitui aquilo que ele diz. Entendimento que nos faz compreender que, se esse sujeito "está preso em relações de produção e em relações de sentido, ele está preso em relações de poder de uma grande complexidade" (FOUCAULT, 2014a, p. 119).

O poder não é visto aqui como repressão, coercitivo ou negativo, mas, conforme mostrado no trabalho de Miriam Pacheco Silva (2007, p. 10), "podemos falar em poder como difuso no social e nas relações". O poder é visto em seu aspecto produtivo, como uma "situação estratégica", é "algo que se exerce" não que se adquire, que tem "miras e objetivos", como evidenciado no HSI (FOUCAULT, 2014a, p. 102-103). É acionando esse conceito de poder, para analisar os discursos docentes mediados pelo livro didático, que uma pesquisa do ano de 2012 indica que “'os discursos verdadeiros' estão mergulhados em relações de poder, produzidas discursivamente e ao mesmo tempo produtoras de discursos, de saberes e de verdades" (SILVA; SIQUEIRA, 2012, p. 4). Dessa forma, a verdade é uma invenção, é vista como um perspectivismo. Considerando esse modo de entender a verdade, outro trabalho problematiza como "a escola tem se constituído como grande lugar em que se processam as produções de verdade sobre o sexo, o gênero e a sexualidade" (SIERRA, 2012, p. 4).

Esse mesmo entendimento de verdade e de relações de poder constitui uma outra pesquisa que nos ajuda a entender a construção dos sujeitos nos seus processos educativos como "um sujeito que é constituído a partir de verdades inventadas às quais se submete ou pode resistir, num jogo em que outras verdades podem ser construídas, podendo também entrar em circulação nos processos de subjetivação (RITTI, 2013, p. 1). Nesse trabalho, aparece um outro conceito que compõe a perspectiva que une os trabalhos do GT23 que utilizam o HSI: resistência. A resistência constitui as relações de poder, já que, em toda relação de poder, ocupa-se uma posição reversível, vez que os "pontos de resistência estão presentes em toda a rede de poder" (FOUCAULT, 2014a, p. 104). A resistência inscreve-se nas relações de poder como "um interlocutor irredutível" (Ibidem).

O entendimento de sujeito, discurso, verdade, poder e resistência, que une essas pesquisas que utilizam o livro HSI, no GT pesquisado, é um marcador importante nas pesquisas em educação. Permite ampliar o próprio entendimento de educação apenas ligado a uma instituição, uma escola mais precisamente, para lançar nosso olhar para outros artefatos que também fabricam sujeitos, educam-nos e 
estão até disputando com a escola, divulgando verdades e constituindo os sujeitos de determinado forma. Constitui-se sujeito a partir dos grupos gays (FERRARI, 2006), da mídia (SCHWENGBER, 2010) e da música (VARGAS, XAVIER, 2013), por exemplo. Dizemos, assim, que o arcabouço foucaultiano provocou inflexões importantes para todos nós que pesquisamos em educação as questões de gênero e sexualidade e permitiu a emergência de problematizações acerca da produção dos sujeitos como uma ação não apenas da escola, mas dos diversos espaços e artefatos que alcançam esse sujeito de formas variadas. Essas pesquisas estão inseridas em um campo sempre muito aberto, pois as técnicas de poder se atualizam, ganham novas formas e funcionamento, de modo que outras pesquisas sempre estão surgindo mostrando essa dinâmica. Os/as autores/as se familiarizam com Foucault, fazem um uso interessado dele para deixálo para trás, para avançar através de um exercício do pensamento que os faz pensar de outros modos.

Se, por um lado, as pesquisas do GT23 referenciadas pelo HSI examinam alguns conceitos e encaminhamentos dados no pensamento foucaultiano, seguindo-os naquilo que eles são úteis e importantes para as diferentes investigações, há, por outro lado, uma fidelidade infiel ou, como disse Veiga-Neto, "um tipo de adesão intelectual condicionada às circunstâncias determinadas pelo próprio ato de aderir" (VEIGANETO, 2014, p. 72). Desse modo, essa fidelidade não diz de abandonar os conceitos construídos pelo autor, ou negá-los, mas parte da "necessidade de constantes atualizações" (VEIGA-NETO, 2014, p. 73). Assim, cada produção do GT23 está imersa no seu próprio tempo, no presente e a partir do contexto brasileiro. Nesse sentido, o modo como o próprio Foucault sugere que ele seja usado - como ferramenta, fogo artifício -, a questão de fazer uma história do presente e o modo como compreendemos educação a partir também do pensamento foucaultiano potencializam a emergência de uma multiplicidade de temas nesse GT23, que vão desde a "Educação Sexual à transexualidade". Entendemos que um pensamento educacional que se abre à problematização do presente e do sujeito, alargando as possibilidades de pesquisa com o as teorizações genealógicas de Foucault, pode instaurar práticas de liberdade nos diversos espaços pedagógicos que funcionam como tecnologias de produção de sujeitos.

Fazemos essa afirmação ancorados no pensamento de Foucault. Se ele investigou tantos modos de subjetivação e, através de suas investigações, continuamos a mostrar esses modos também no presente, fazemos isso como um investimento para que nós mesmos e os próprios sujeitos pensem acerca dos poderes e verdades que os constituem de determinada forma e possamos problematizar: Por que penso o que eu penso? Por que me constituo dessa forma e não de outra? Dessa maneira, podemos acionar um objetivo principal às nossas investigações, tal qual Foucault nos ensinou:

\footnotetext{
"O objetivo principal, hoje, não é descobrir, mas recusar o que nós somos. Devemos imaginar e construir o que poderíamos ser para nos livrarmos dessa espécie de 'dupla obrigação' política que são a individualização e a totalização simultânea das estruturas do poder moderno" (FOUCAULT, 2014b, p. 128).
} 
Nesse sentido, somos instigados pelo autor a "promover novas formas de subjetividade, recusando o tipo de individualidade que se impôs durante vários séculos" (FOUCAULT, 2014b, p. 128).

Os trabalhos, por darem lugar para essas novas formas de subjetividade, também nos possibilitam pensar que eles fazem parte de um movimento, de uma disposição a não acomodação, colocando sob suspeita o que classificamos como "normal". Essa talvez seja uma das lições mais aprendidas na "História da Sexualidade I": que o sujeito racional, coerente e unificado não existe e que é preciso libertar nossos desejos de qualquer repressão. Nessa obra, Foucault vai nos convocar a pensar a sexualidade como um dispositivo, algo construído e que tem uma história, de maneira que trabalhar com a sexualidade como tendo uma história implica pensar que ela é resultado de diferentes discursos. O autor, portanto, vai argumentar que a história da sexualidade só pode ser construída, se levarmos em consideração a história dos discursos e das relações de saber-poder que atravessam nossos entendimentos de sexualidade.

A identificação com a "não-acomodação" nos trabalhos do GT 23 também dizem da história de constituição desse campo no Brasil, demonstrando como o espaço do GT vai se construindo em diálogo com o movimento no campo. É exemplo disso a entrada das discussões da teoria Queer e as discussões da transexualidade, que vão aparecer somente em 2008 (CÉSAR, 2008), tomando um fôlego maior nos anos seguintes com os trabalhos mais dedicados à transexualidade e realidade brasileira (CÉSAR, 2009; TORRES, 2013; SANTOS, 2013; SANTOS, 2015; SEVILLA, 2015; SANTOS, 2017; SANTOS, 2019). Contribuindo com esse diálogo, há ainda o único trabalho dedicado à família homoparental (REALI, 2009). Essas são, de fato, discussões muito recentes no cenário das relações de gênero, sexualidade e educação no Brasil, datadas de meados da década de 2010, adquirindo força na década seguinte.

Respondendo à atualidade dessas temáticas, Maria Rita César (2008), recorrendo aos estudos de Michel Foucault, já defendia a entrada dessas discussões no campo da Educação pela não acomodação dos sujeitos a uma sexualidade normatizada: "todos/as são sujeitos que subvertem as expectativas em relação ao sistema sexo/gênero e podem abrir um diálogo para um currículo ou uma pedagogia queer. Por que queer? Para que possamos viver uma vida não fascista” (CÉSAR, 2008, p.1). A não acomodação desses sujeitos nos convoca a pensar a escola e a educação a partir de uma outra perspectiva, a partir da denúncia que esses corpos e suas transgressões fazem desse espaço. É a "História da Sexualidade I" que é chamada para a percepção do teor transgressivo que a expressão queer adquiriu.

Os leitores[as] que buscavam uma maior compreensão acerca da história do sexo e das práticas sexuais através dos tempos, na tentativa de entenderem o binômio entre a repressão sexual e a liberação do sexo nos anos setenta, se surpreendiam com as teses do autor sobre o conceito de sexualidade como uma criação discursivoinstitucional, cuja função seria o controle dos indivíduos e das populações produzindo a normalização dos corpos. (CÉSAR, 2008, p. 6-7).

A obra é parte de um projeto mais amplo de problematizar como nos tornamos o que somos. Nesse investimento em questionar nossas formas de saber, as relações de poder que nos constituem e nossas ações 
sobre os outros e sobre nós mesmos, Foucault vai rompendo com os silêncios, vai propondo novas e provocativas questões. A sexualidade é parte dessa proposta de questionar as verdades e as normalidades. Falando sobre a importância de Michel Foucault para a discussão da sexualidade, Guacira Lopes Louro nos diz:

A respeito da sexualidade, duvidou do suposto silêncio e repressão que a teriam cercado e afirmou que, em vez disso, essa era uma questão sobre a qual muito se falava e há muito tempo. Assumindo sua ótica, passamos a afirmar que a sexualidade era e é construída discursivamente (LOURO, 2009, p. 136).

O que a citação reforça é a influência de Foucault como um instaurador de discursividade, como aquele que foi capaz de produzir uma nova perspectiva de análise para as sexualidades, diferente do que era apresentado no campo da Psicologia. Ele instaurou uma nova forma vinculada aos discursos, à sexualidade como dispositivo discursivo, como uma incessante vontade de saber e produzir saberes sobre os sujeitos, seus corpos, desejos, emoções, práticas, ensinando-nos que essa incessante produção discursiva que deu origem à sexualidade está atravessada o tempo todo pela relação saber-poder. Como Sílvio Gallo (2004) argumenta, o instaurador de discursividade não se limita aos textos que escreve, estando seus escritos implicados em produzir novos campos de investigação, novas possibilidades de pensar e novas enunciações discursivas.

Sua obra costuma ser didaticamente dividida em três fases: a primeira marcada por As palavras e as coisas (1966); a segunda por Vigiar e Punir (1975); e a terceira pela História da sexualidade -, publicada em três volumes, o primeiro deles (A vontade de saber) tendo aparecido em 1976.

A primeira fase é marcadamente epistemológica, buscando desvendar o solo do qual brotam os saberes; a segunda, podemos dizer que é política, pois Foucault procura mostrar a íntima relação entre os saberes e os poderes; a terceira, volta-se para a Ética quando, ancorado em Nietzsche, o francês vai propor que cada um faça de sua vida uma obra de arte (GALLO, 2004, p. 80).

Na citação de Sílvio Gallo, podemos perceber que a terceira fase dialoga com as anteriores, o que nos possibilita pensar a sexualidade como uma construção discursiva que está implicada com um jogo de reconstrução, de renovação e reativação constante de discursos. Um jogo que está centrado na relação dos sujeitos com esses discursos e nas suas possibilidades de resistência e de subversão ao que está dado como natural e normal no campo das relações de gênero e sexualidade. Os trabalhos do GT 23, quando dão lugar a esses sujeitos que "inauguram" modos resistentes e subversivos de ser e estar no mundo, estão no jogo da produção de discursos novos no campo da educação, não somente a educação escolarizada, mas principalmente um sentido de educação que diz da produção de sujeitos em meio a instituições, discursos, saberes e poderes. Embora Foucault não tenha discutido diretamente temas como transexuais e travestis na escola (CÉSAR, 2009), homoparentalidade e escola (REALI, 2009), professores e professoras que transitam nas fronteiras do gênero e sexualidade (ALMEIDA E MOTA, 2009), tais discussões foram possíveis de ser instauradas a partir da "História da Sexualidade I", para além dessa obra, transformando- 
se em temas novos, resultando em novos discursos que são infiéis a Michel Foucault e que inauguram novas formas de subjetividade.

A terceira fase de Foucault, em que a discussão da sexualidade toma protagonismo, pode ser considerada a que "mais elementos possam nos trazer para, indo além do diagnóstico do presente, pensarmos possíveis futuros para a Educação" (GALLO, 2004, p. 95). Nesse sentido, a "História da Sexualidade I" cumpre sua função no GT 23, na medida em que é uma obra tomada na sua perspectiva ética de pensar novas formas de produzir a vida. Uma vida que valha a pena ser vivida, denunciando as mazelas que nos assolam no interior de instituições como a escola, a universidade, e em suas relações de saberpoder. Ressaltamos, ainda, que depois da "História da Sexualidade I", as três obras mais citadas no GT 23 são “Arqueologia do Saber", "Vigiar e Punir" e "Microfísica do Poder" são, respectivamente. Não por acaso, são as obras que marcam as fases da arqueologia e da genealogia e que nos convidam a problematizar a educação para além da disciplinarização. São obras que nos incitam a construir escolas e processos educativos mais responsáveis com ética, possibilitando processos de subjetivação que resultem numa educação comprometida com o cuidado de si mesmo e do outro, construindo novas formas de produção de si e de relações com os outros. Esse é um aspecto que nos interessa na utilização que é feita da "História da Sexualidade I", ou seja, como ela é tomada para pensar outras formas de ser e estar no mundo, investindo nas subversões e resistências as normas de gênero e sexualidade.

\section{Subversão e resistência}

Podemos pensar que o conceito de "subversão" se deve muito à obra de Michel Foucault, sobretudo à "História da Sexualidade I", em que o autor vai demonstrar a construção da sexualidade ligada aos discursos e às relações de saber-poder, contribuindo para que outros autores e autoras ampliem essa compreensão, de forma que possam afirmar que gênero é uma forma de regulação social (BUTLER, 2006). Uma regulação social advinda dos dispositivos próprios para tal função, dos quais podemos destacar, regulações legais, institucionais, educacionais, dentre outras que agem com a intenção de regular os sujeitos. Durante muito tempo, a tendência foi tomar esse processo de regulação dos sujeitos pelo gênero e sexualidade a partir de uma certa separação entre o poder de regulação, compreendido quase como uma estrutura única, coesa e autônoma, e o gênero. O equívoco era pensar que esses dispositivos de regulação agiam reprimindo e moldando os sujeitos aos seus gêneros e sexualidades, transformando-os em homens masculinos heterossexuais e mulheres femininas heterossexuais.

Assim, explorando os clássicos livros da história da sexualidade e ampliando suas potencialidades como problematizações, os trabalhos (CÉSAR, 2009; TORRES, 2013) que se dedicam a tomar a subversão como possibilidade vêm colocando sob suspeita essa separação entre o poder de regulação e os sujeitos, 
com seus gêneros e sexualidade, demonstrando que não há uma regulação anterior ou mesmo autônoma que vai criar o gênero. Ao contrário disso, os trabalhos demonstram que esses sujeitos só existem a partir da sua sujeição às regulações de gênero. A nossa sociedade do enquadramento não nos permite escapar dessa regulação de gênero como processo de constituição dos sujeitos.

$\mathrm{Na}$ "História da Sexualidade I", Foucault vai trabalhar esse entendimento de regulação da sexualidade e subjetivação a partir das relações de poder, para dizer que o poder não é simplesmente opressor das subjetividades, ele é, também, parte da sua constituição. O poder é positivo e criativo, além de estar diretamente ligado aos mecanismos de regulação e aos processos disciplinares que ele é capaz de construir e de manter, de tal maneira que esses discursos reguladores são responsáveis, ao mesmo tempo, pela construção dos sujeitos detentores dos "seus gêneros" e pela produção da sujeição (FOUCAULT, 1988).

Interessado nas relações entre os jogos de saber-poder e a produção das subjetividades, Foucault (1988) vai demonstrar que é na própria maquinaria do poder que se encontram as forças de resistência e subversão, tão importantes para o desafio e a potencialidade da transformação. Só existem relações de poder porque há sempre a possibilidade de resistência, uma certa insubmissão que é condição imanente dessas relações de poder, que guarda e permite as invenções e transgressões como forças capazes de subverter esse diagrama de forças. Por isso, é importante entender que não é contra o poder que as subversões e resistências se originam, mas é contra os efeitos desse poder num espaço aberto que elas adquirem vida, sendo acionadas como estratégias de luta.

Essas forças de subversão e resistência nos chamaram atenção no conjunto de trabalhos que toma as transexualidades como tema de investigação. Em todos eles (CÉSAR, 2009; TORRES, 2013; SANTOS, 2013; SANTOS, 2015; SEVILLA, 2015; SANTOS, 2017; SANTOS, 2019), a escola é o campo em que esses sujeitos - que subvertem e resistem - circulam, sejam como alunas e alunos, ou como professoras e professores. A escola é apresentada como espaço da resistência e da subversão da norma corpo-gênerosexualidade. Se a sexualidade é uma construção histórica e discursiva, é um dispositivo, como nos aponta Foucault, a escola é parte desse processo. Na escola, também aprendemos e ensinamos sexualidade.

Embora Foucault não tenha se dedicado a essa relação entre a construção da sexualidade e a cultura escolar, suas obras ajudaram a fomentar as investigações sobre a escola nas suas múltiplas relações com a construção do gênero e sexualidade. Conforme observamos, as pesquisas que aparecem no GT 23, dedicadas a essas relações, se apropriam de suas obras, sobretudo da "História da Sexualidade I", em diálogo com "Vigiar e Punir" e "Microfísica do Poder", para investigar sobre os processos disciplinares, a arquitetura, o currículo, o exame e classificações, os exercícios corporais, as punições e as premiações. Mais recentemente, essas obras passaram a ajudar nos trabalhos que discutem a relação entre biopoder nas escolas, para pensar o governo das populações a partir do dispositivo discursivo da sexualidade, sobretudo 
a partir das ideias de prevenção, saúde, sexualidade e corpo. A subversão não se dá em qualquer espaço, mas numa instituição marcada pela disciplina e controle dos corpos, pelos mecanismos de construção dos sujeitos e seus pertencimentos a corpos biológicos, a desejos heteronormativos e sexualidades tidas como "normais".

Por que a instituição escolar recusa o nome social, produzindo a evasão? A resposta pode ser imediata: se a escola é o lugar por excelências das formas de normalização dos corpos, os corpos de transexuais e travestis representam o outro da norma, aquele/a que sempre escapará das teias disciplinares e biopolíticas do governamento escolar. Ou ainda: por que estes corpos não normativos colocam em cheque as certezas estabelecidas pelo sistema sexo-corpo-gênero, que a escola, mesmo diante de programas de educação sexual, diversidade sexual e combate ao preconceito, ainda insiste em preservar (CÉSAR, 2009, p. 2-3).

Apoiando-se em Foucault, Maria Rita César (2009) vai colocar uma problemática atual nas escolas brasileiras, que é o processo de expulsão das transexuais das escolas, numa demonstração de poder e prazer que marca essa instituição disciplinar. Poder-prazer que se reforçam no controle, na vigilância dos corpos e sujeitos com suas sexualidades, prazer de classificar e nomear e mesmo o poder-prazer em minar as resistências. As transexuais passam a ser "o outro da norma, aquele/a que sempre escapará das teias disciplinares e biopolíticas do governamento escolar". Marco Antônio Torres (2013) também se dedica a pensar os sujeitos que, durante muito tempo, ficaram afastados das escolas, que sofreram processos de expulsão dessa instituição, não entendida como espaço de transgressão às normas de corpo-gênerosexualidade.

Travestis e transexuais são sujeitos desclassificados por discursos que os produzem a partir da desordem social e psíquica, pois têm sido associados à prostituição e aos diagnósticos psicológicos e psiquiátricos, entre outros dispositivos orientados pela heteronormatividade. Quando esses sujeitos começam a emergir na escola como docentes temos evidenciada uma questão, quais as formas de ingresso e sustentação das professoras travestis e transexuais femininas no ambiente escolar? (TORRES, 2013, p. 1).

A escola continua sendo o espaço de problematização da presença desses sujeitos que não se enquadram, que resistem e subvertem a norma. Não somente alunas e alunos, mas também professoras e professores. Essas transgressões à norma só podem ser entendidas a partir da noção sexo como dispositivo, um entendimento construído a partir da "História da Sexualidade I" e que vai marcar esses trabalhos que estão pensando a constituição desses sujeitos que escapam ao limite da compreensão de corpos somente como homens ou como mulheres, vivenciando exclusivamente o desejo heterossexual.

No entanto, a imposição dessa presença às instituições escolares, não ocorre sem um esforço da própria instituição em regulá-la. As pessoas que fabricam seus corpos e identidades de gênero, diferente daquele atribuído a partir da genitália ao nascer e que ousam adentrar os espaços e tempos escolares como estudantes, em geral, "causam" estranhamentos, incômodos, curiosidades e mexericos, perturbando a ordem da escola. (SANTOS, 2013, p. 1-2). 
A autora segue argumentando acerca da importância dos estudos de Foucault para além do que ele próprio pesquisou, para ampliar seu escopo de análise e construir algo autoral no que diz respeito à transexualidade.

\begin{abstract}
A possibilidade de se perguntar pela normalidade constituiu-se nas condições de possibilidade também para a invenção da transexualidade. Como um dos desdobramentos do dispositivo da sexualidade (FOUCAULT, 1988), o dispositivo da transexualidade organiza os saberes, as práticas e os discursos que as sustentam produzindo a patologização da experiência transexual e um personagem: a/o verdadeira/o transexual. (SANTOS, 2013, p. 6).
\end{abstract}

O que está em jogo nesses trabalhos é o que Santos (2013) nomeia como "possibilidade para a invenção da transexualidade". As possibilidades de se inventar estão ligadas às possibilidades de resistir e de subverter o que está destinado aos sujeitos. As resistências e as subversões em Foucault dizem da liberdade do sujeito. "História da Sexualidade I" é a continuidade das questões abertas pelo autor, interessado nos processos de constituição dos sujeitos a partir da análise do poder. O último Foucault ou também chamado de terceiro Foucault ${ }^{\text {vi }}(1978-1984)$ se dedica mais particularmente a estudar das dinâmicas das resistências, nos seus variados aspectos, sobretudo em diálogo com a complexa rede de relações de poder na atualidade. É esse último Foucault que é tomado nesses trabalhos que se dedicam a problematizar a constituição das transexualidades, como uma questão atual e candente nas escolas brasileiras.

Para essas investigações em torno das experiências de subversão ao gênero - a transexualidade -, "História da Sexualidade I" é utilizada como se fosse para construir um campo problemático de investigação a partir dos antecedentes históricos de construção das sexualidades no Ocidente para pensar as resistências e suas possibilidades de êxito. Nesse terceiro Foucault, o interesse se concentra em pensar os combates e as lutas associando-as às relações de poder. É aí que as resistências ao poder passam a ser consideradas como formas de manutenção das liberdades dos sujeitos. E, talvez, por isso "História da Sexualidade I" seja a obra mais utilizada nos trabalhos que discutiram a transexualidade, porque ela é porta de entrada para essa última fase de Foucault, uma fase muito diferente das anteriores em que o indivíduo pouco ou nada podia fazer nas lutas de transformação do mundo social e político (BRANCO, 2001).

A “História da Sexualidade I", nesses trabalhos destinados a pensar as transexualidades, convidanos a problematizar e mesmo restaurar o lugar e o papel dos sujeitos éticos, sensíveis e resistentes no cenário educacional brasileiro. Um sujeito que resiste porque é livre, que pode ser considerado, ontologicamente, livre porque tem sensibilidade, razão e poder de modificar sua realidade. Talvez esse seja o maior ensinamento de Foucault, ao problematizar a história da sexualidade como dispositivo discursivo atravessado por saber-poder: que resistência e liberdade dos sujeitos devem ser pensadas na prática das lutas sociais, na precariedade da vida, na contingência dos acontecimentos e na mobilidade das construções sociais e políticas. 
Nesse sentido, acreditamos que os trabalhos apresentados no GT 23 aprenderam e ampliaram o pensamento foucaultiano nos seus encontros com as escolas, com o sistema educacional brasileiro e com o entendimento de que educação é algo que acontece para além das escolas, envolvido nos processos de constituição dos sujeitos. Os trabalhos se debruçam sobre as práticas, dedicam-se a analisar as estratégias que constroem essas práticas de subversão e resistência, enfim, as diferentes maneiras que são acionadas pelos indivíduos, livremente, em suas lutas, negociações, confrontos, projetos para se constituírem como sujeitos de suas práticas ou mesmo recusarem as práticas que lhes são impostas. Assim como Foucault, que acreditava na liberdade humana, os trabalhos que se utilizam desse autor mantêm viva essa crença na liberdade como mola propulsora de transformação e resistência do que chamamos de realidade.

\section{Considerações finais}

É importante recuperar dois pontos que insistimos ao longo do texto. Dois pontos que convergem na demonstração de que o GT 23 - Gênero, Sexualidade e Educação - é um espaço de criação a partir do pensamento foucaultiano. O primeiro ponto é a defesa da utilização infiel a Foucault para produzir algo próprio e autoral no que diz respeito ao contexto educacional brasileiro, sabendo-se valer dos conceitos de sujeito, saber-poder, verdade, resistência, para problematizá-los a partir do presente, de situações, práticas e relações do cotidiano educacional. A infidelidade a Foucault reforça sua classificação como instaurador de discursividade, uma vez que estamos sendo capazes de produzir discursos para além dele, a partir dele, com ele. O segundo ponto é o trabalho com as possibilidades de subversão e resistências, como práticas necessárias para o enfrentamento da situação atual de ataques às relações entre gênero, sexualidade e educação. Os trabalhos apresentados no GT23, ao longo desses 15 anos, nos ensinaram que não é inútil nos revoltarmos, diante de uma insistência e investimento pela continuidade. Esse é o desafio que podemos tirar como lição desses trabalhos, ou seja, manter viva a resistência criativa, aquele que é capaz de afirmar a vida, de defender as lutas em torno de novas possibilidades de ser e estar no mundo. Um GT que, no seu conjunto, nos mostra o quanto a área de conhecimento Gênero, Sexualidade e Educação é recente, e o quanto ela - a área - é ameaçadora para as forças conservadoras, mas também o quanto ela está ameaçada.

Mostramos, tomando um foco de análise como central - as transexualidades - que a resistência e a subversão ao que nos é instituído como corpo-gênero-sexualidade é que possibilitam as transformações e novas formas de pensar a escola, a educação, a relação entre sujeitos. Não queremos dizer com isso que somente as transexualidades possam ser consideradas como atos de resistência e subversão, mas, ao contrário disso, que elas só foram possíveis de ser entendidas como tais a partir da ampliação do entendimento de sexualidade inaugurado pela obra "História da Sexualidade I", em que os discursos e as relações de poder com seus efeitos sobre o sujeito tomou o centro das problematizações de que como nos 
tornamos o que somos. Os trabalhos do GT 23, de forma geral, nos possibilitaram pensar a utilização de Foucault no campo da Educação a partir de duas perspectivas, tanto os assujeitamentos quanto os processos de subjetivação. No primeiro, temos o sujeito sendo subjetivado pelas forças do poder, já no segundo, o foco está na ação desse sujeito sobre si mesmo. Os trabalhos se apropriam dessas duas perspectivas que não são excludentes, ou seja, que se misturam para nos constituir. Mas é contra as diferentes formas de assujeitamento e de subjetivação que estamos lutando para recusar o que nós somos.

\section{Referências}

ALMEIDA, Edwana Nauar de. Corpos escalpelados na escola: entre marcas físicas, sociais e escolares. In: 38. Reunião Anual da ANPEd, São Luís, 2017.

ALMEIDA, Neil Franco Pereira \& MOTA, Maria Veranilda Soares. Docências que transitam pelas fronteiras das sexualidades e do gênero: a escola como espaço de imposições de poderes e resistências. In: 32. Reunião Anual da ANPEd, Caxambu, 2009.

BALESTRIN, Patrícia Abel. A sexualidade num curso normal - seus tempos e "contra-tempos". In: $30^{a}$. Reunião Anual da ANPEd, Caxambu, 2007.

BASSALO, Lucélia de Moraes Braga. Heteronormatividade ou reconhecimento? professores e professoras diante da homossexualidade. In: 32 ${ }^{a}$. Reunião Anual da ANPEd, Caxambu, 2009.

BRANCO, Guilherme Castelo. As resistências ao poder em Michel Foucault. Revista Trans/Form/Ação, vol. 24. n. 1, Marília, 2001.

BUTLER, Judith. Deshacer el género. Barcelona: Paidós, 2006.

CAMPOS, Miriam Piber. Identidades “anormais": a (des)construção dos corpos "deficientes”. In: $29^{a}$. Reunião Anual da ANPEd, Caxambu, 2006.

CASTRO, Roney Polato de. Professores(as) sexualidade e educação sexual: produzindo sujeitos nos contextos do programa de educação afetivo-sexual (PEAS). In: $31^{a}$. Reunião Anual da ANPEd, Caxambu, 2008.

CASTRO, Roney Polato de. Escritas-narrativas de estudantes problematizando relações de gênero e sexualidades. In: 36 ${ }^{a}$. Reunião Anual da ANPEd, Caxambu, 2013.

CASTRO, Roney Polato de. Formação docente, experiência religiosae sexualidades: problematizações. In: 37. Reunião Anual da ANPEd, Caxambu, 2015.

CÉSAR, Maria Rita de Assis. Quatro intervenções para uma pedagogia queer. In: $31^{a}$. Reunião Anual da ANPEd, Caxambu, 2008.

CÉSAR, Maria Rita de Assis. Um nome próprio: transexuais e travestis nas escolas brasileiras. In: $32^{a}$. Reunião Anual da ANPEd, Caxambu, 2009. 
CRUZ, Elizabete Franco. Infâncias, Adolescências e AIDS. In: 29. Reunião Anual da ANPEd, Caxambu, 2006.

FERNANDES, Letícia Prezzi. Família e relações de gênero: um olhar através do direito. In: $32^{a}$. Reunião Anual da ANPEd, Caxambu, 2009.

FERRARI, Anderson. A "bicha banheirão" e o "homossexual militante": grupos gays, educação e a construção do sujeito homossexual. In: 29ª Reunião Anual da ANPEd, Caxambu, 2006.

FOUCAULT, Michel. História da Sexualidade I: a vontade de saber. Rio de Janeiro: Graal, 1988.

FOUCAULT, Michel. História da Sexualidade I: a vontade de saber. Rio de Janeiro: Paz e Terra, 2014a.

FOUCAULT, Michel. Genealogia da Ética, Subjetividade e Sexualidade. Rio de Janeiro: GEN, 2014b.

FOUCAULT, Michel. Editorial: “O ‘efeito Foucault’ em Educação”. Revista Pró-Posições, vol. 25, no 2 (74), p. 15-21 | maio/ago. 2014.

FOUCAULT, Michel. Gerir os ilegalismos. In: FOUCAULT, Michel. Michel Foucault: entrevistas a Roger Pol-Droit. São Paulo: Graal, 2006. p.41-52.

FOUCAULT, Michel. Verdade e Poder. In: FOUCAULT, Michel. Microfísica do poder. 2.ed. Rio de Janeiro: Graal, 1981.

GALLO, Sílvio. Repensar a Educação: Foucault. Revista Educação \& Realidade, vol. 29, nº 1, Porto Alegre: UFRGS, 2004.

. Editorial: “O 'efeito Foucault' em Educação. Pro-Posições |v. 25, n. 2 (74) | P. 15-21 | maio/ago. 2014.

GOETTEMS, Lisiane; SCHWENGBER, Maria Simone Vione; WISNIEWSKI, Rudião Rafael. As diversidades sexuais na escola: (in)junções discursivas entre a religião e o estado laico. In: $38^{a}$. Reunião Anual da ANPEd, São Luís, 2017.

KLEIN, Carin. Juventudes em biopolíticas contemporâneas. In: 39 ${ }^{a}$. Reunião Anual da ANPEd, Niterói, 2019.

LOURO, Guacira Lopes. Foucault e os estudos queer. In: RAGO, Margareth, VEIGA-NETO, Alfredo. Para uma vida não-fascista. Belo Horizonte: Autêntica, 2009.

MEIRELES, Gabriela Silveira. O que dizem as crianças sobre meninos e meninas?: anunciando o jogo das construções, desconstruções e reconstruções das dicotomias de gênero na educação infantil. In: $32^{a}$. Reunião Anual da ANPEd, Caxambu, 2009.

MORESCO, Marcielly Cristina. O corpo “fala” politicamente: as performatividades das/nas ocupações secundaristas do Paraná. In: 38ª Reunião Anual da ANPEd, São Luís, 2017.

MOREIRA, Jasmine. Impactos da 'ideologia de gênero’ na geração de políticas educacionais para a população LGBT. In: $38^{a}$. Reunião Anual da ANPEd, São Luís, 2017. 


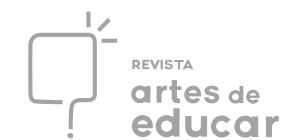

NEVES, Paulo Rogério da Conceição. Violência, traição e gênero: uma briga de meninas em uma escola privada. In: 35a. Reunião Anual da ANPEd, Caxambu, 2012.

NEVES, Regiane Farias. Educação feminina e os devires da sexualidade em Antônia Cudefacho. In: $39^{a}$. Reunião Anual da ANPEd, Niterói, 2019.

PARREIRA, Fátima Lúcia Dezopa; SILVA, Elenita Pinheiro de Queiroz. Discursos de bolsistas do programa institucional de bolsa de iniciação à docência sobre sexualidade. In: $37^{a}$. Reunião Anual da ANPEd, Caxambu, 2015.

NOGUEIRA, Juslaine de Fátima Abreu. Dispositivo da sexualidade e psiquiatrização da educação: notas farmacobiopolíticas sobre o corpo. In: 37ª Reunião Anual da ANPEd, Caxambu, 2015.

PEREIRA, Angélica Silvana. Barbie, Max Steele os heróis que estão em você: consumo e pedagogias de gênero na produção da criança em tempos de (in)tolerância. In: $38^{a}$. Reunião Anual da ANPED, São Luís, 2017.

PORTINARI, Denise. A gentrificação do queer e as intensificações do biopoder. In: $37^{a}$. Reunião Anual da ANPED, Caxambu, 2015.

REALI, Noeli Gemelli. Homoparentalidade e escola: que conjugação é essa? In: $32^{a}$. Reunião Anual da ANPED, Caxambu, 2009.

RIBEIRO, Gabriela Chicuta. Gênero, sexualidade e diversidade sexual na educação física escolar. Uma cartografia das práticas discursivas em escolas paranaenses. In: $35^{a}$. Reunião Anual da ANPED, Caxambu, 2012.

RIBEIRO, Cláudia Maria \& FILHA, Constantina Xavier. Trajetórias teórico-metodológicas em 10 anos de produção do GT 23 da Associação Nacional de Pós-Graduação e Pesquisa em Educação - ANPED. Revista Periódicus, 2a . edição, Salvador: UFBA, 2014.

RITTI, Rosalinda Carneiro de Oliveira. “Todo dia eu penso: meu Deus, onde foi que eu errei?”: os desafios de ser mãe na periferia. In: 36 ${ }^{a}$. Reunião Anual da ANPED, Caxambu, 2013.

RIZZATO, Liane Kelen. Percepções docentes sobre a homofobia na escola: entre dissonâncias e continuidades. In: 33 ${ }^{a}$ Reunião Anual da ANPED, Caxambu, 2010.

SCHWENGBER, Maria Simone Vione. Pobres meninas "ricas" com a gravidez. In: $32^{a}$. Reunião Anual da ANPED, Caxambu, 2009.

SCHWENGBER, Maria Simone Vione. Os meus filhos e os deles: os filhos da esperança. In: $37^{a}$. Reunião Anual da ANPED, Caxambu, 2015.

SANTOS, Dayana Brunetto Carlin dos. A escola como empreendimento biopolítico de governo dos corpos e subjetividades transexuais. In: 36 ${ }^{a}$. Reunião Anual da ANPED, Caxambu, 2013. 
SANTOS, Dayana Brunetto Carlin dos. Corpos e subjetividades trans na escola e nos movimentos sociais: a reinvenção das tentativas de captura por meio das normativas oficiais. In: $37^{a}$. Reunião Anual da ANPED, Caxambu, 2015.

SANTOS, Dayana Brunetto Carlin dos. Docências trans: entre a decência e a abjeção. In: $38^{a}$. Reunião Anual da ANPED, São Luís, 2017.

SANTOS, Sandro Prado. Cartografias das experiências de pessoas trans com os territórios da Educação em Biologia. In: 39ª Reunião Anual da ANPED, Niterói, 2019.

SANTOS, Luã Sarcinelli; HADDOCK-LOBO, Rafael. Entre errâncias: Derrida e Deleuze. Revista Humus. Vol. 8. Número 14. 2018.

SEVILLA, Gabriela Garcia. Pedagogias de gênero e sexualidade em artefatos culturais: reflexões sobre uma experimentação. In: 37ª Reunião Anual da ANPED, Caxambu, 2015.

SIERRA, Jamil Cabral. O governamento da diversidade sexual e o desafio de uma ética/estética pósidentitária para a teorização político-educacional LGBT. In: $35^{a}$. Reunião Anual da ANPED, Caxambu, 2012.

SILVA, Mirian Pacheco. Quando o estranho é o professor: narrativas sobre sexualidade e o currículo de formação de professores. In: 30 ${ }^{a}$. Reunião Anual da ANPED, Caxambu, 2007.

SILVA, Andréa Costa da; SIQUEIRA, Vera Helena Ferraz de. Sexualidade na escola mediada pela literatura: apropriações docentes. In: 31 . Reunião Anual da ANPED, Caxambu, 2008.

SILVA, Andréa Costa da; SIQUEIRA, Vera Helena Ferraz de. Sexualidade e gênero: discursos docentes mediados pelo livro paradidático. In: 35ª Reunião Anual da ANPED, Caxambu, 2012.

SILVA, Elenita Pinheiro de Queiroz. Corpo e sexualidade no ensino de ciências: experiências de sala de aula. In: 35. Reunião Anual da ANPED, Caxambu, 2012.

SOUSA, Bernardina Santos Araújo de. Os manuais de conduta e a escrita feminina no início do século xx: o que desvelam as narrativas? In: $31^{a}$. Reunião Anual da ANPED, Caxambu, 2008.

SOUZA, Marcos Lopes de. O PIBID como espaço formativo de desarranjos, reinvenções e pluralizações dos gêneros e das sexualidades. In: 37ª Reunião Anual da ANPED, Caxambu, 2015.

TORRES, Marco Antônio. Docência, transexualidades e travestilidades: a emergência rede Trans Educ Brasil. In: 36 ${ }^{a}$. Reunião Anual da ANPED, Caxambu, 2013.

VARGAS, Juliana Ribeiro de \& XAVIER, Maria Luisa Merino. A feminilidade em discurso: mídias musicais contemporâneas produzindo modos de ser jovem e mulher. In: $36^{a}$. Reunião Anual da ANPED, Caxambu, 2013.

VEIGA NETO, Alfredo. Foucault \& Educação. Belo Horizonte: Autêntica, 2003.

VEIGA-NETO, Alfredo; RECH, Tatiana Luiza. Esquecer Foucault? Pro-Posições. v. 25, n. 2 (74)| p. 67 82 | maio/ago. 2014. 
XAVIER, Constantina Filha. "Qual destas moças é você?” O autoconhecimento produzido pelos testes da imprensa feminina - décadas de 50 a 70 do século XX. In: 29ª Reunião Anual da ANPED, Caxambu, 2006. XAVIER FILHA, Constantina. Catálogo eletrônico de produções bibliográficas sobre educação sexual e de gênero - décadas de 1930 a 1985. In: 32ª Reunião Anual da ANPED, Caxambu, 2009.

Recebido em: 06/02/2020

Aceito em: 13/07/2020

Notas:

i Pós doutor em Educação e Cultura Visual pela Universidade de Barcelona/Espanha. Doutor em Educação pela Unicamp. Professor na Faculdade de Educação da UFJF. Professor permanente do PPGE/UFJF. E-mail: ferrarianderson13@gmail.com Juiz de Fora ORCID: https://orcid.org/0000-0002-5681-0753

ii Doutorando no Programa de Pós-Graduação em Educação: Conhecimento e Inclusão Social da Faculdade de Educação da Universidade Federal de Minas Gerais. Mestre em Educação pela Universidade Federal de Sergipe. Membro do Grupo de Estudos e Pesquisas em Currículos e Culturas (GECC) e do Observatório da Juventude (UFMG). E-mail: danilodinamarques@ hotmail.com Minas Gerais ORCID: https://orcid.org/0000-0003-3222-3172

iii Esse número não leva em consideração os trabalhos apresentados na $33^{a}$ reunião anual, de 2010, em função da falta de acesso na página, sendo a única reunião que não é possível ter acesso aos trabalhos. Também não leva em consideração a totalidade de trabalhos aprovados e apresentados na $39^{\mathrm{a}}$ reunião anual, de 2019 , visto que, a partir desse ano, os autores e autoras não eram obrigados a disponibilizar os trabalhos para serem publicados na página da ANPEd.

iv A escolha do GT23 para a presente pesquisa é um posicionamento político em resistência aos recentes ataques a esse campo do conhecimento já consolidado na Educação.

${ }^{\vee}$ Estamos considerando aqui como livro não somente os livros escritos por Foucault como tal, mas também os cursos dados por ele, posteriormente transformados em livros, e as diversas entrevistas compiladas e transformadas em livro.

vi A definição de último ou terceiro Foucault acontece para fins didáticos. É uma maneira de separar todo o conjunto de obras do autor, basicamente, em três fases: arqueológica (primeiro Foucault), genealógica (segundo Foucault), ética (terceiro/último Foucault). Cada uma dessas fases ele se debruça de maneiras, e com focos diferenciados para seus objetos de pesquisa, conferindo qualidades específicas aos conceitos e modos metodológicos de operar com as questões de pesquisa. Para mais detalhes ver: Veiga-Neto (2003). 